\title{
Hepatitis tóxica inducida por fármacos en un paciente con diálisis peritoneal
}

\author{
Ana Hurtado Cárceles, Irene Hurtado Cárceles, Julián Navarro Martínez, Diana Manzano Sánchez, Eulalia \\ Cárceles Legaz, Isabel Romero Espinosa
}

Hospital Universitario Virgen de la Arrixaca. Murcia. España

\section{Introducción}

Las peritonitis son las principales complicaciones en diálisis peritoneal (DP) y precisan de tratamiento antibiótico empírico precoz que con frecuencia incluye el uso de la vancomicina siendo el hígado el órgano que interviene en la transformación de la mayoría de los medicamentos lo que puede conllevar a toxicidad hepática ${ }^{1}$. Aunque la hepatitis infecciosa es la más frecuente también puede darse la originada por la metabolización de algunos medicamentos. Los antibióticos son un grupo de medicamentos muy utilizado, pero los efectos adversos hepatotóxicos deben considerarse poco frecuentes dada la amplísima variedad de esta prescripción farmacológica. Las reacciones hepatotóxicas a ciertos antibióticos pueden ayudar a los profesionales a identificar tempranamente las causas de hepatotoxicidad, la mayoría de las cuales son idiosincrásicas, con antecedentes de alergia en ocasiones, por lo que no pueden ser predichas. La importancia de la hepatotoxicidad inducida por antimicrobianos radica en la grave morbimortalidad de la patología ${ }^{2}$. Entre los tóxicos hepáticos impredecibles se encuentra la vancomicina ${ }^{1}$. Consideramos presentar este caso por la frecuencia con que se utiliza la vancomicina en DP.

PALABRAS CLAVE:

- TRANSAMINASAS

- HEPATITIS TÓXICA

- PERITONITIS

- DIÁLISIS PERITONEAL

\section{Correspondencia:}

Eulalia Cárceles Legaz

Alameda Capuchinos, 9, $1^{\circ}$ A. 30002 Murcia. España

E-mail: lalicarceles@yahoo.es.

\section{Caso clínico}

Presentamos un varón de 71 años, con antecedentes de hipertensión, diabetes mellitus tipo 2, enfermedad de Von Willebrand con múltiples ingresos por hemorragia digestiva y con enfermedad renal crónica secundaria glomerulonefritis, en programa de DP desde el 2011.

Tuvo cinco episodios de peritonitis, el último fue en diciembre del 2015 recibiendo tratamiento con vancomicina intraperitoneal, con buena evolución de la peritonitis. El último día del tratamiento consultó por ictericia y malestar general con elevación de las transaminasas y la bilirrubina. Tras la suspensión del fármaco hubo mejoría clínica y normalización de la analítica.

En marzo del 2016, tuvo nuevo episodio de peritonitis, decidiéndose tratamiento empírico con teicoplanina y tobramicina. A los 3 días de estar con el tratamiento consulta por malestar generalizado, vómitos, diarrea, fiebre e ictericia.

\section{Evolución}

No hay una prueba específica para el diagnóstico definitivo por lo que hay que realizar varias pruebas.

Al ingreso: La TA fue de 178/74 y la temperatura $38^{\circ} \mathrm{C}$.

Líquido Peritoneal: en el recuento del líquido peritoneal; el aspecto del líquido biológico era ligeramente turbio con $278 \mathrm{cel} / \mathrm{uL}$, siendo el $56 \%$ leucocitos polimorfonucleares y el $44 \%$ leucocitos mononucleares. (Tabla 1).

Hematimetría de sangre total: serie blanca, leucocitos $17.400 \mathrm{uL}$. 
Tabla 1. Recuentos del líquido peritoneal.

\begin{tabular}{l|c|c|c|}
\hline & \multicolumn{3}{|c}{ LÍQUIDO PERITONEAL } \\
\hline & Rto. cel/uL & PMN \% & MN \% \\
\hline INGRESO & 278 & 56 & 44 \\
\hline ALTA & 36 & 53 & 47 \\
\hline
\end{tabular}

Bioquímica Automatizada: bilirrubina total de 3,34 $(0,05-1,20) \mathrm{mg} / \mathrm{dL}$, bilirrubina directa $2,98(0,10-0,20)$ $\mathrm{mg} / \mathrm{dL}$ y bilirrubina indirecta $0,36(0,02-0,25) \mathrm{mg} / \mathrm{dL}$, G0T 128 (5-40) U/L, GPT 112 (5-41) U/L, GAMMA GT 514 (10-71) U/L, LDH 339 (135-225) U/L. Proteína C Reactiva 7,26 (0,00-0,50) mg/dL. (Tabla 2).

EI TAC abdominal informó de una moderada hepatomegalia con $24 \mathrm{~cm}$ de diámetro.

En los hemocultivos aislamos Eschericia coli y en cultivo del líquido peritoneal hallamos Enterococo faecalis.

Durante el ingreso se le suspendió la teicoplanina e inicio tratamiento con Linezolid y Piperacilina/Tazobactam.

A los 15 días: Líquido peritoneal: En el recuento del líquido peritoneal; el aspecto era claro con $36 \mathrm{cel} / \mathrm{uL}$, siendo el $53 \%$ leucocitos polimorfonucleares y el $47 \%$ leucocitos mononucleares. (Tabla 1).

Hematimetría de sangre total, serie blanca: leucocitos 6.660 uL. En Bioquímica automatizada: bilirrubina total 0,52 mg/dL. GOT $15 \mathrm{U} / \mathrm{L}$, GPT $20 \mathrm{U} / \mathrm{L}$, GAMMA GT 134 U/L y LDH 129 U/L. PRUE Proteína C Reactiva 0,77 mg/dL. (Tabla 2).

La serología vírica y los marcadores tumorales fueron normales.
Al alta se constató la normalización de la GOT y GPT con mejoría en descenso de la Gamma GT y se constató el descenso de la PCR.

Las revisiones posteriores, en consulta, se objetivó una normalización completa de los parámetros de función hepática.

\section{Discusión}

La hepatitis, proceso inflamatorio, puede producirse por toxinas, virus, medicamentos y agentes químicos. La hepatitis tóxica es una entidad rara responsable de menos del $5 \%$ de ictericia o hepatitis aguda en la población general ${ }^{2}$. Los síntomas son similares a la hepatitis vírica, ictericia, náuseas, vómitos, cansancio, dolor abdominal, fiebre, aumento de las transaminasas y la bilirrubina ${ }^{3}$. La gravedad es variable y existen pocos casos con evolución hacia la cirrosis o la insuficiencia hepática terminal, que obliguen a un trasplante hepáti$\mathrm{Co}^{4}$. El diagnostico de la hepatitis tóxica se basa en la exclusión de otras causas y la relación temporal de los síntomas con el consumo del fármaco, no existe un tratamiento específico, la mejoría del cuadro se produce tras la retirada del fármaco implicado.

La vancomicina es uno de los antibióticos más utilizados para el tratamiento de la peritonitis en DPCA. Sus principales efectos secundarios son la nefrotoxicidad y la ototoxicidad. La teicoplanina es también un glucopeptido de espectro similar a la vancomicina pero con menores efectos secundarios.

En nuestro paciente fueron descartadas todas las causas conocidas, presentó un cuadro de hepatitis aguda tras tratamiento con vancomicina y tuvo un nuevo epi-

Tabla 2. Evolución de las analíticas en sangre total.

\begin{tabular}{|c|c|c|c|c|c|c|c|}
\hline & \multirow{2}{*}{$\begin{array}{l}\text { HEMATIMETRÍA } \\
\text { Leucocitos } \\
(4500-11000) \text { uL }\end{array}$} & \multicolumn{6}{|c|}{ BIOQUÍMICA AUTOMATIZADA } \\
\hline & & $\begin{array}{c}\text { B. Total } \\
(0,05-1,20) \mathrm{mg} / \mathrm{dL}\end{array}$ & $\begin{array}{c}\text { GOT } \\
(5-40) \mathrm{U} / \mathrm{L}\end{array}$ & $\begin{array}{c}\text { GPT } \\
(5-41) \mathrm{U} / \mathrm{L}\end{array}$ & $\begin{array}{l}\text { Gamma GT } \\
(10-71) \text { U/L }\end{array}$ & $\begin{array}{c}\text { LDH } \\
(135-225) \mathrm{U} / \mathrm{L}\end{array}$ & $\begin{array}{c}\text { PCR } \\
(0,00-0,50) \mathrm{mg} / \mathrm{dL}\end{array}$ \\
\hline INGRESO & 17.400 & 3,34 & 128 & 112 & 514 & 339 & 7,26 \\
\hline ALTA & 6.660 & 0,52 & 15 & 20 & 134 & 129 & 0,77 \\
\hline
\end{tabular}


sodio tras la administración de teicoplanina. En ambos casos la resolución, del cuadro tras retirada de los fármacos, fue completa.

\section{Conclusiones}

Aunque las hepatitis toxica secundaria a glucopeptidos es una entidad infrecuente, su conocimiento es importante por la frecuencia del uso de la vancomicina y por la potencial gravedad.

Recibido: 25 agosto 2016

Revisado: 4 septiembre 2016

Modificado: 25 octubre 2016

Aceptado: 1 noviembre 2016

\section{Bibliografía}

1. Juan-Carlos, Muñoz, Juan-Fernando, Correa, Gonzalo, Zuleta, John, Londoño, Marcela, Botero et al. Hepatotoxicidad detectada en un hospital de Medellín. Acta médica Colombiana, Octubre-Diciembre 2008. 33 (4): 261-267.

2. Mastai, Ricardo, Turbay, Maximiliano, Anders, Margarita, Chao, Sara, Mc Cormack, Lucas, Olaiz, Emiliano. Hepatitis aguda asociada al consumo de Herbalife ${ }^{\circledR}$ a propósito de un caso. Acta Gastroenterológica Latinoamericana. Diciembre 2008, 38 (4): 274-277.

3. Basteen Z. Vildosola, H, Lozano, Z, Verona, R, Vargas, G. Hepatitis tóxica colestásica por terbinafina. Rev. Gastroenterol. 2004; 24: 357-362.

4. Ponce García I, Arráez Ruiz N, Hermida Lazcano I. Paciente con fracaso hepático agudo tras toma de Amoxicilina-Ácido Clavulánico. Rev. Clín. Med. Fam. 2007; 2 (2): 92-96. 